\title{
Improved Synthesis of Aryltrialkoxysilanes via Treatment of Aryl Grignard or Lithium Reagents with Tetraalkylorthosilicates
}

\author{
Amy S. Manoso, Chiljin Ahn, Arash Soheili, Christopher J. Handy, Reuben Correia, \\ W. Michael Seganish, and Philip DeShong*
}

\section{SUPPORTING INFORMATION}

Table of Contents

General Experimental

References

${ }^{1} \mathrm{H}$ NMR of 2-(Triethoxysilyl)anisole

${ }^{1} \mathrm{H}$ NMR of 2-(Trimethoxysilyl)anisole

${ }^{1} \mathrm{H}$ NMR of 3-(Triethoxysilyl)anisole

${ }^{1} \mathrm{H}$ NMR of 4-(Triethoxysilyl)anisole

${ }^{1}$ H NMR of 4-(Triethoxysilyl)-1,2-(methylenedioxy)benzene

${ }^{1} \mathrm{H}$ NMR of 2-(Triethoxysilyl)toluene

${ }^{1} \mathrm{H}$ NMR of 2-(Trimethoxysilyl)toluene

${ }^{1} \mathrm{H}$ NMR of 3-(Triethoxysilyl)toluene

${ }^{1} \mathrm{H}$ NMR of 4-(Triethoxysilyl)toluene

${ }^{1} \mathrm{H}$ NMR of Triethoxyphenylsilane

${ }^{1} \mathrm{H}$ NMR of 4-(Triethoxysilyl)thioanisole

${ }^{1} \mathrm{H}$ NMR of 3-(Triethoxysilyl)thiophene

${ }^{1} \mathrm{H}$ NMR of 5-(Triethoxysilyl)indole

${ }^{1} \mathrm{H}$ NMR of 5-(Triethoxysilyl)-1-methyl-indole

${ }^{1} \mathrm{H}$ NMR of 2-Furyltriethoxysilane 
Thin layer chromatography (TLC) was performed on $0.25 \mathrm{~mm}$ Merck silica-coated glass plates treated with a UV-active binder, with the compounds being visualized in one or more of the following manners: UV (254 nm), iodine, or vanillin/sulfuric acid charring. Flash chromatography was performed using thick-walled glass columns and medium-pressure silica gel (Davisil ${ }^{\circledR} 200-425$ mesh) as described by Still.

Infrared band positions are given in reciprocal centimeters $\left(\mathrm{cm}^{-1}\right)$ and relative intensities are listed as br (broad), vs (very strong), s (strong), m (medium), or w (weak).

Nuclear magnetic resonance $\left({ }^{1} \mathrm{H},{ }^{13} \mathrm{C}\right)$ chemical shifts are reported in parts per million $(\square)$ downfield from tetramethylsilane (TMS). Coupling constants ( $J$ values) are reported in Hertz (Hz), and spin multiplicities are indicated by the following symbols: $s$ (singlet), $d$ (doublet), $t$ (triplet), q (quartet), $m$ (multiplet), br s (broad singlet).

Methylene chloride $\left(\mathrm{CH}_{2} \mathrm{Cl}_{2}\right)$, tetraethyl orthosilicate $\left(\mathrm{Si}(\mathrm{OEt})_{4}\right)$, and tetramethyl orthosilicate $\left(\mathrm{Si}(\mathrm{OMe})_{4}\right)$ were each distilled from calcium hydride. Tetrahydrofuran (THF) and diethyl ether $\left(\mathrm{Et}_{2} \mathrm{O}\right)$ were each distilled from sodium-benzophenone ketyl. Methanol (MeOH) and ethanol (EtOH) were stored over molecular sieves.

Aryl halides, heteroaryl halides and alkyl halides were prepared by literature procedure as noted, or purchased from Acros or Aldrich and purified using the method of Perrin ${ }^{2}$ prior to use. The compounds 2-bromoquinoline ${ }^{3}, 3$-bromoquinoline ${ }^{4}$, and 5-bromo-2-methoxypyridine ${ }^{5}$ were each prepared according to the literature procedure.

$n$-Butyllithium (1.6 M solution in hexane), and $t$-butyllithium (1.5 M solution in pentane) were purchased from Acros and used as received. The alkyllithium concentration was confirmed by titration with diphenylacetic acid using the method of Kofron. ${ }^{6}$ Magnesium turnings were cleaned as follows: enough turnings were placed in a beaker to form a thin layer. Dilute $\mathrm{HCl}$ solution $(0.1 \mathrm{M})$ was added to just cover the magnesium turnings. The turnings were stirred until bubbling ceased and then the solution was decanted off and the process repeated three times or until the metal had a shiny mirror appearance. The turnings were then washed in the beaker three times each with water, ethanol, and diethyl ether. Finally, the turnings were dried in an oven at $120^{\circ} \mathrm{C}$ for five minutes. 
Glassware used in the reactions described below was dried for a minimum of $12 \mathrm{~h}$ in an oven at $120{ }^{\circ} \mathrm{C}$. All reactions were run under an atmosphere of nitrogen or argon at room temperature unless otherwise noted.

All compounds were determined to be $>95 \%$ pure by ${ }^{1} \mathrm{H}$ NMR unless otherwise noted.

\section{References}

(1) Still, W. C.; Kahn, M.; Mitra, A. J. Org. Chem. 1978, 42, 2923-2924.

(2) Perrin, D. D.; Armarego, W. L. F.; Perrin, D. R. Purification of Laboratory Chemicals; 2 ed.; Pergamon: New York, 1980.

(3) Young, T. E.; Amstutz, E. D. J. Am. Chem. Soc. 1951, 73, 4773-4775.

(4) Balicki, R.; Kozlowska, M.; Sobotka, W. Bull. Pol. Acad. Sci.-Chem. 1986, 34, 281-287.

(5) Kunishima, M.; Friedman, J. E.; Rokita, S. E. J. Am. Chem. Soc. 1999, 121, 4722-4723.

(6) Kofron, W. G.; Baclawski, L. M. J. Org. Chem. 1976, 41, 1879-1880. 


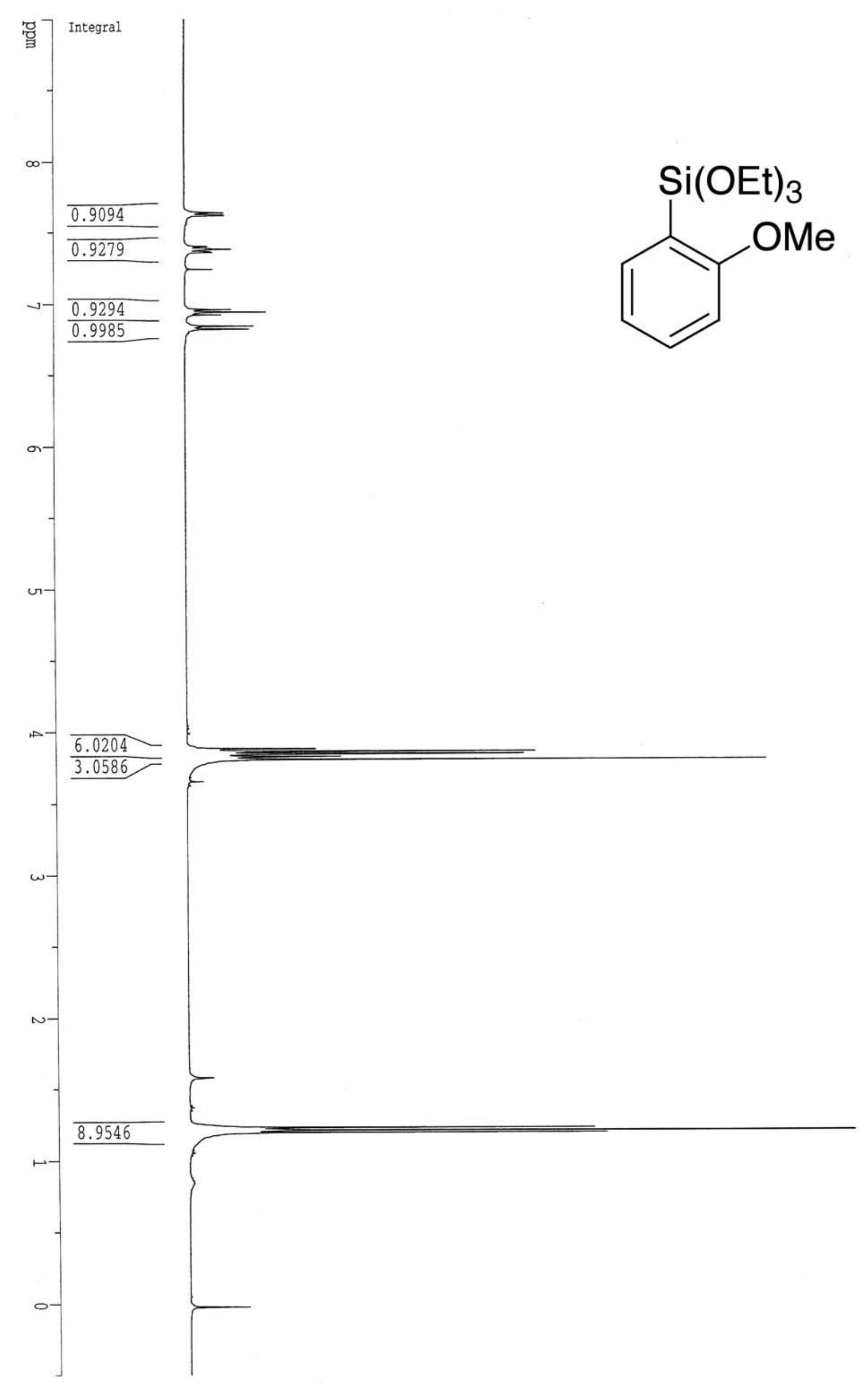

S4 

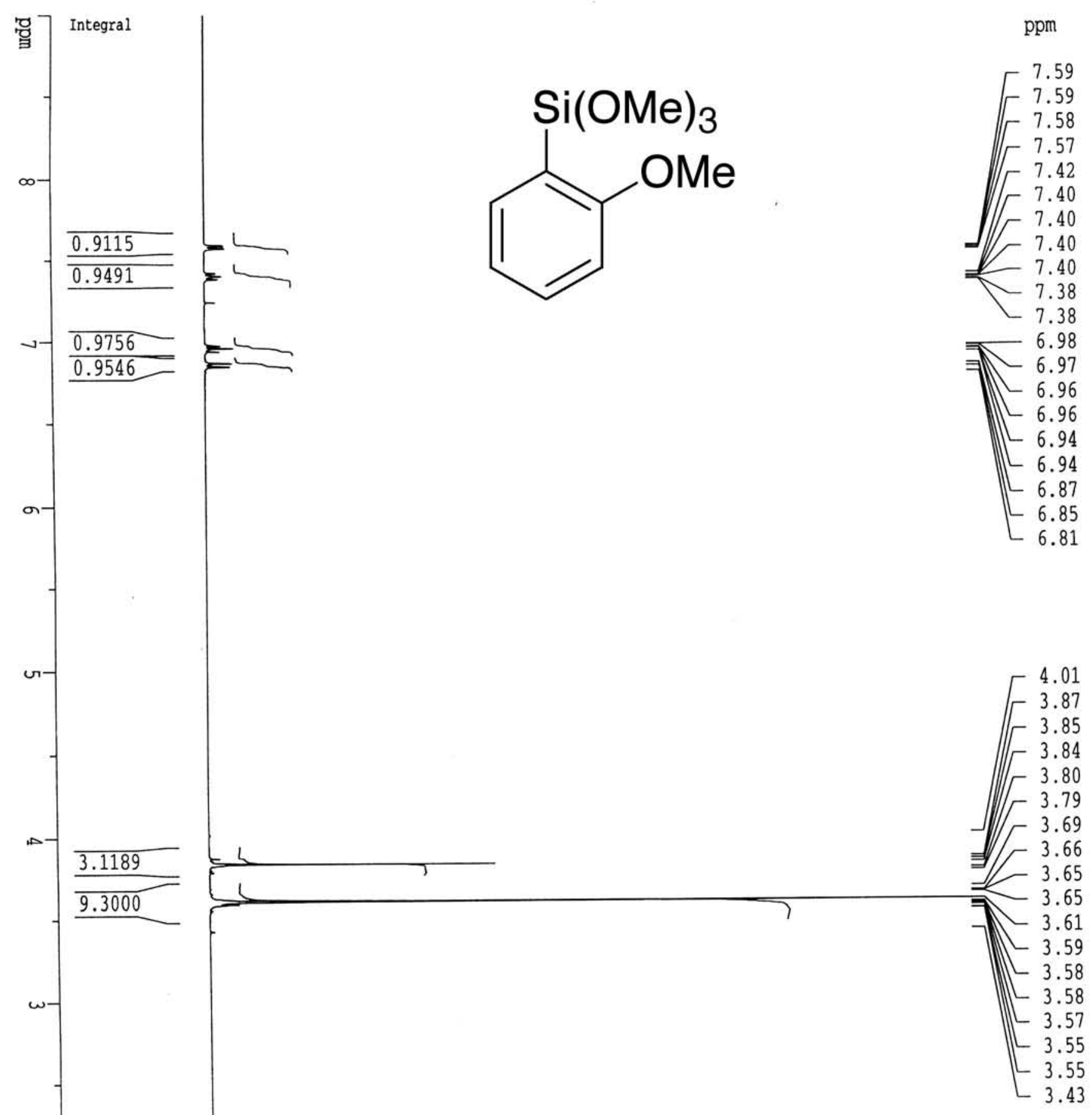$$
\text { . }
$$ 


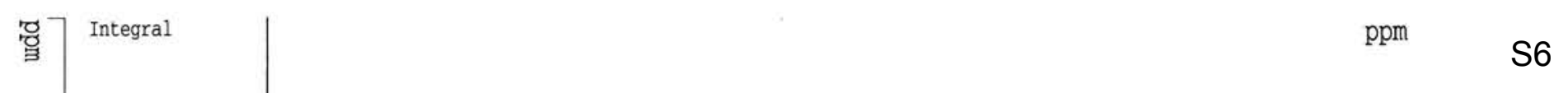
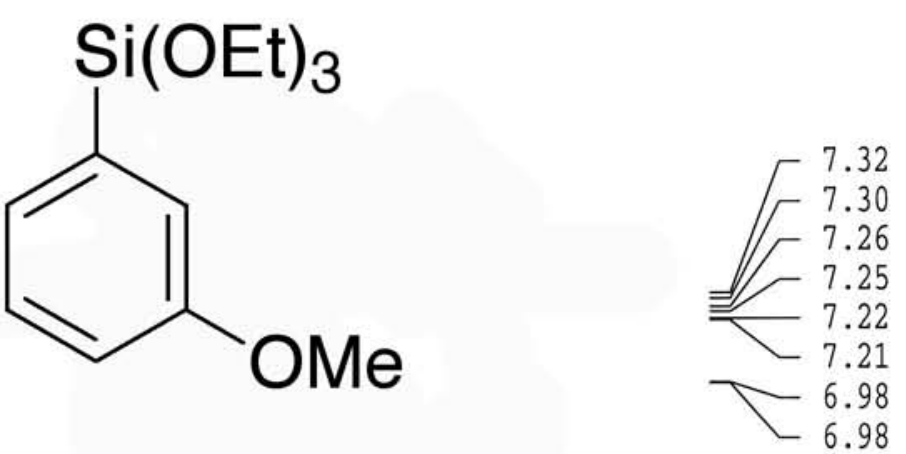

$\left[\begin{array}{l}3.90 \\ -3.88 \\ -3.86 \\ 3.85 \\ 3.81\end{array}\right.$
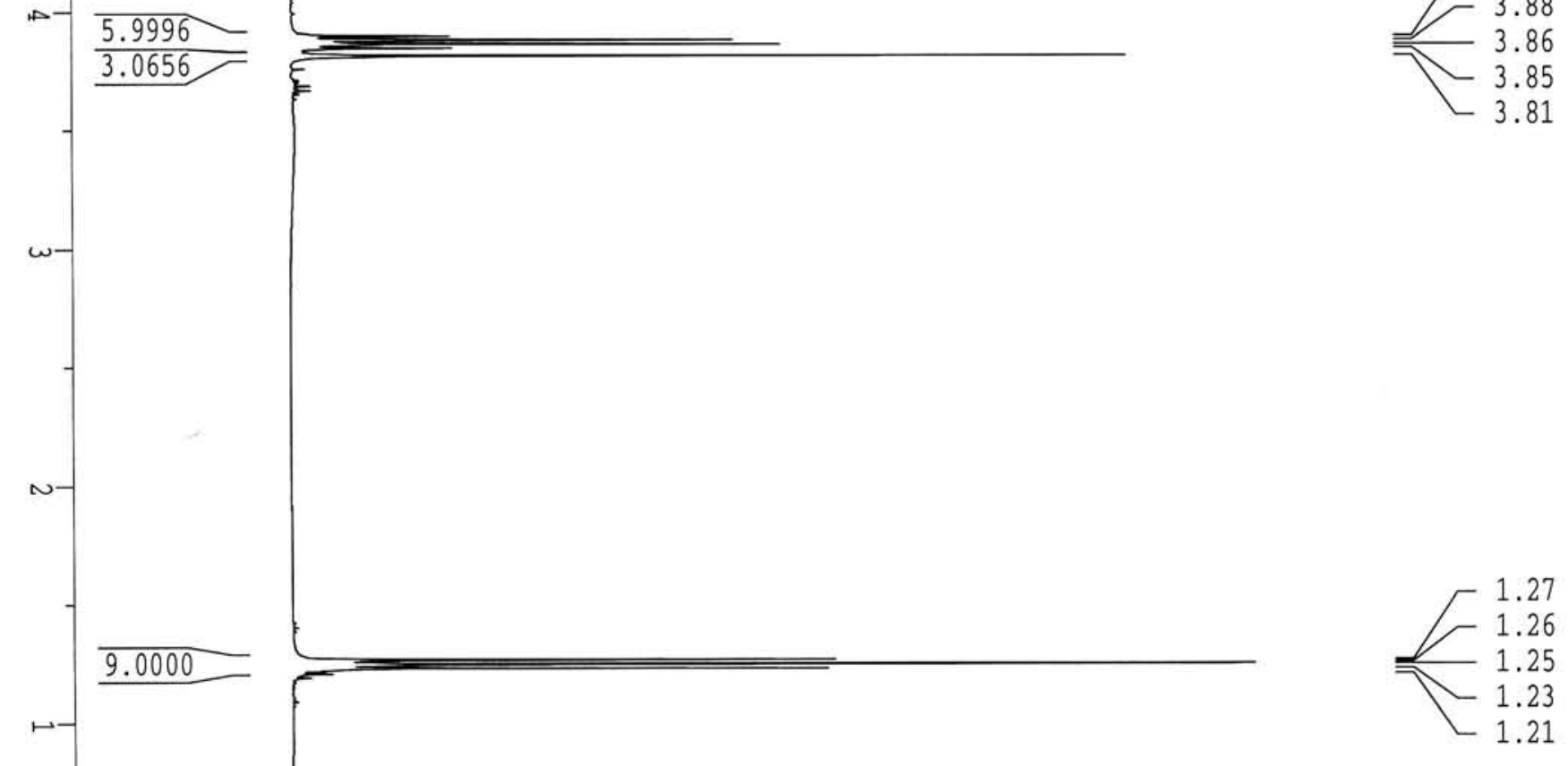


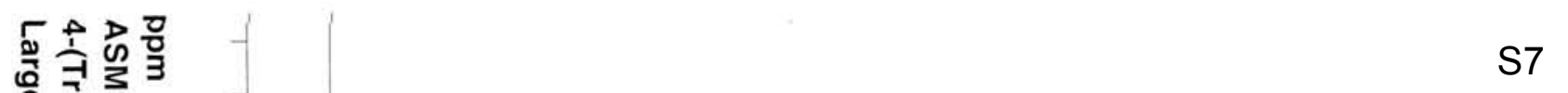

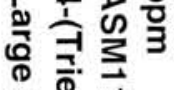

II

t.

.

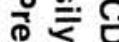

II:

.

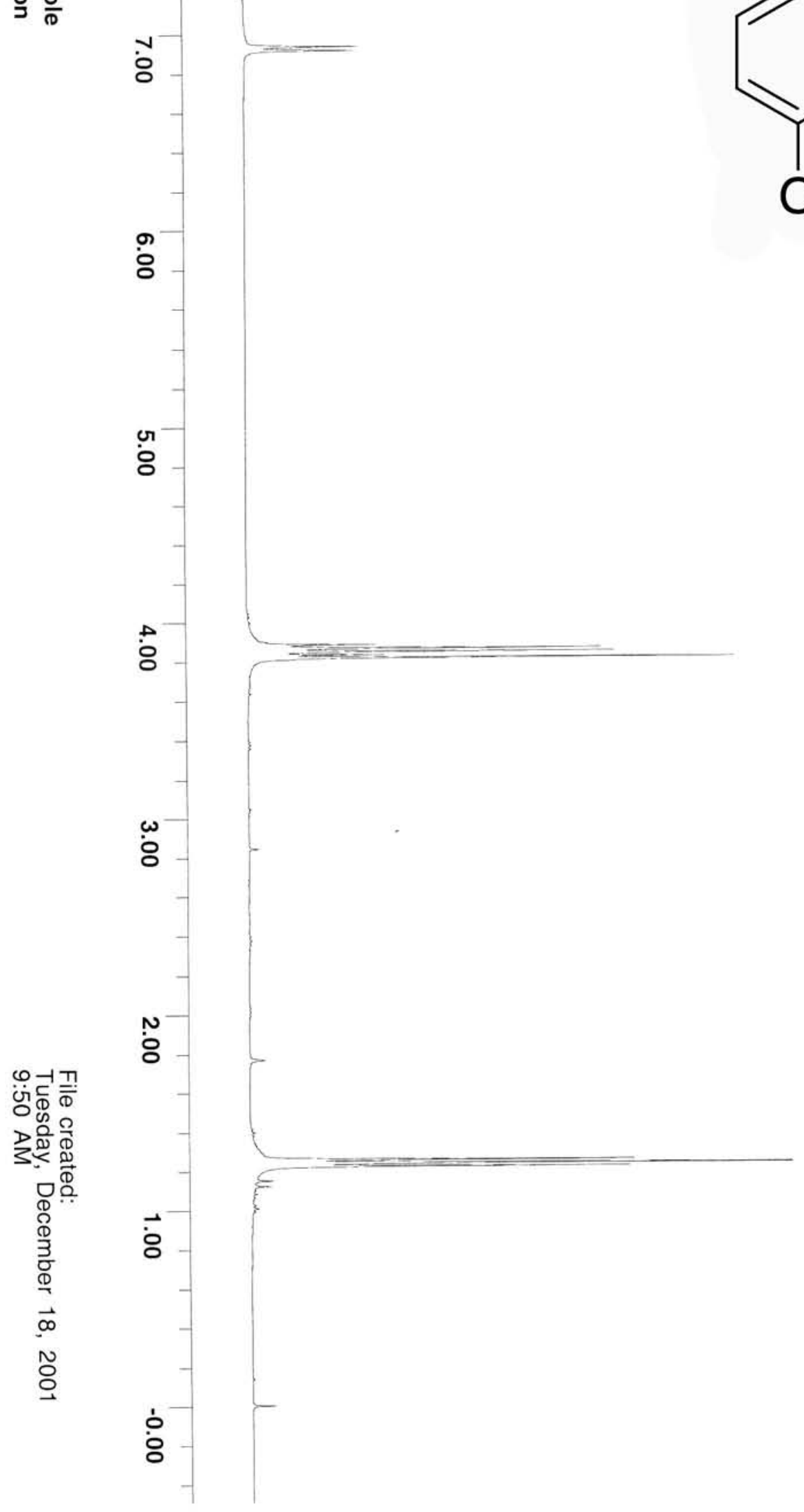

$\mathrm{Si}(\mathrm{OEt})_{3}$

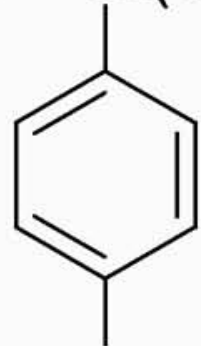

OMe 

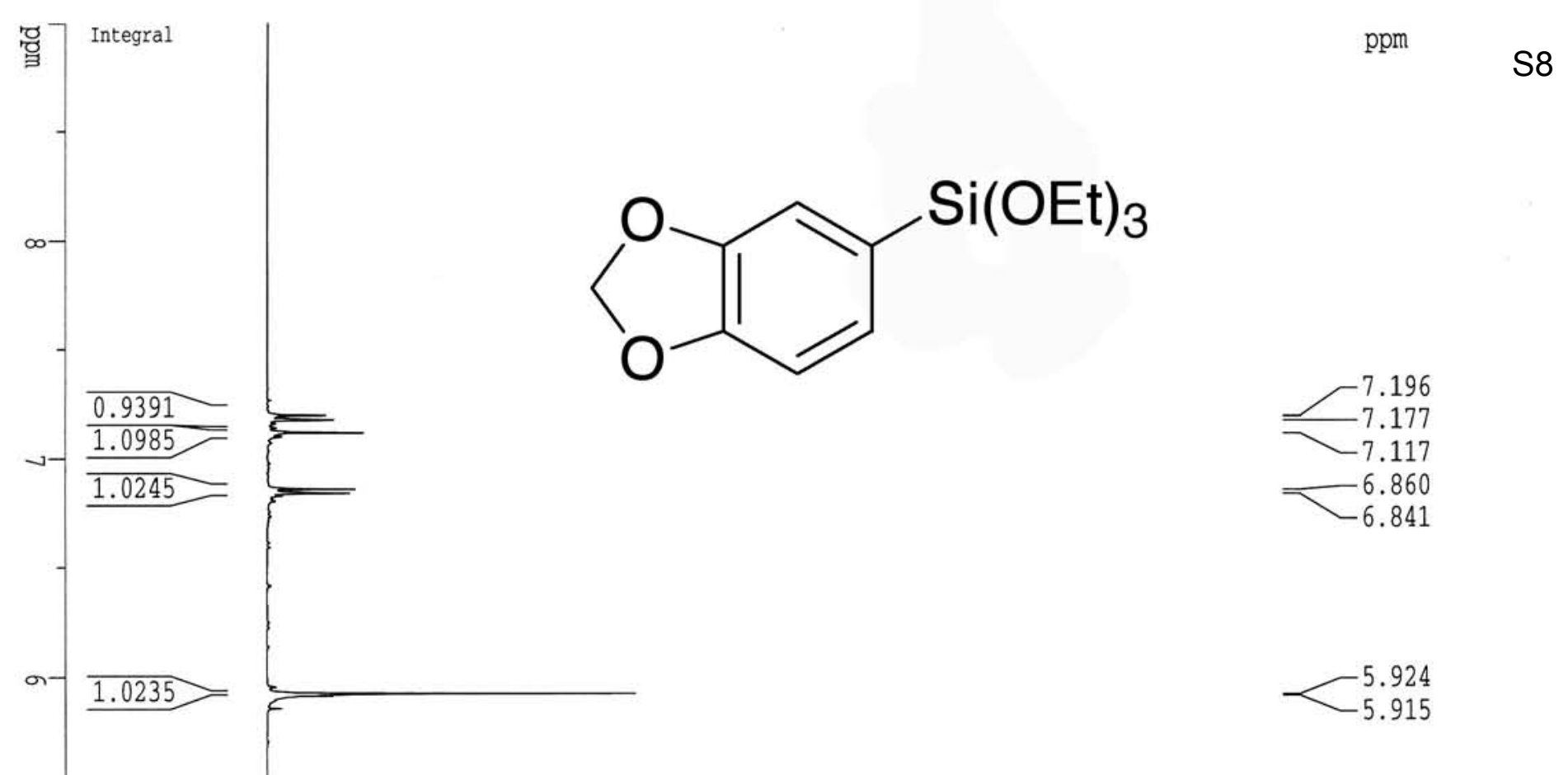

$-3.882$

$-3.865$

$-3.847$

$-3.830$

$-1.257$ 


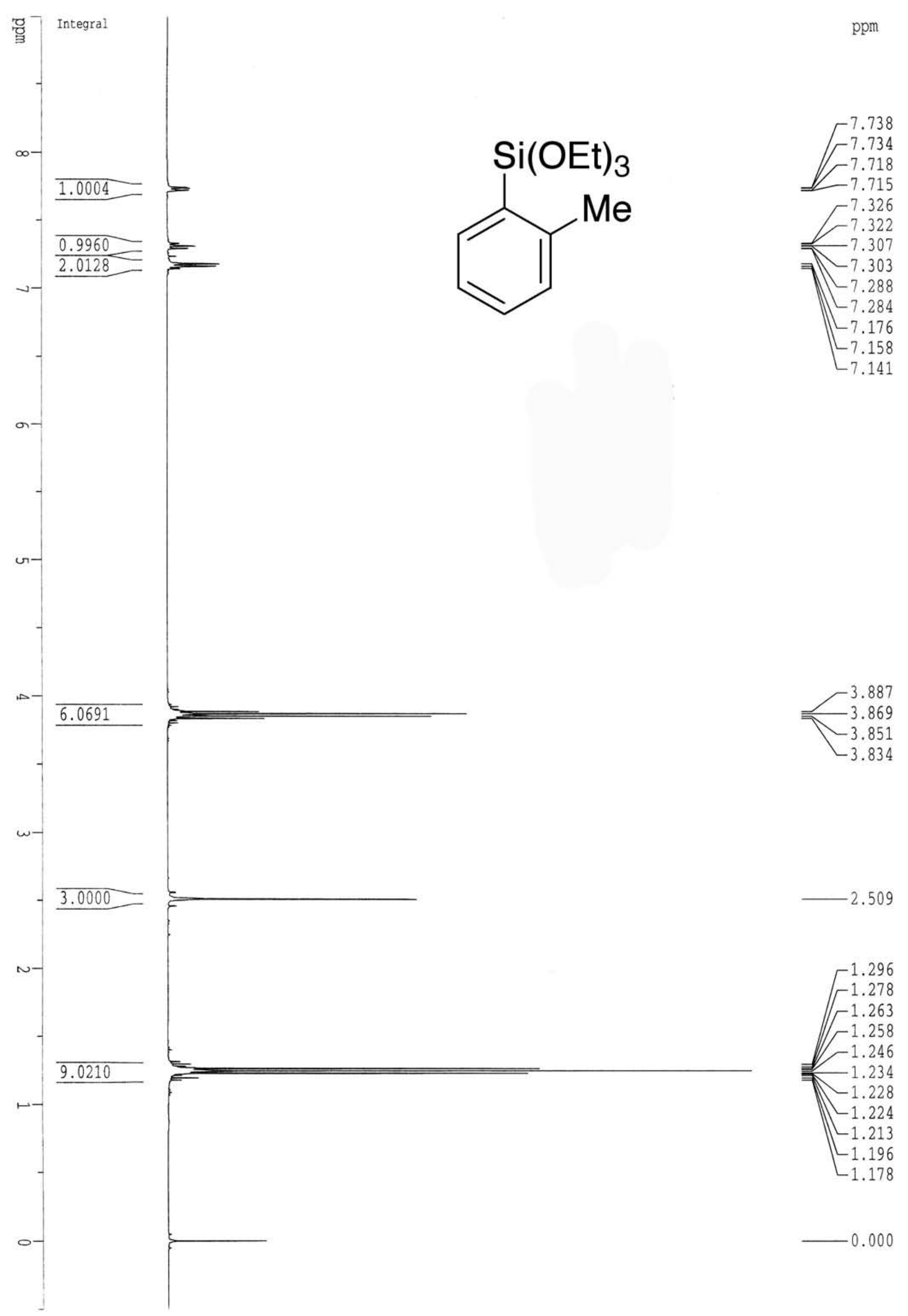



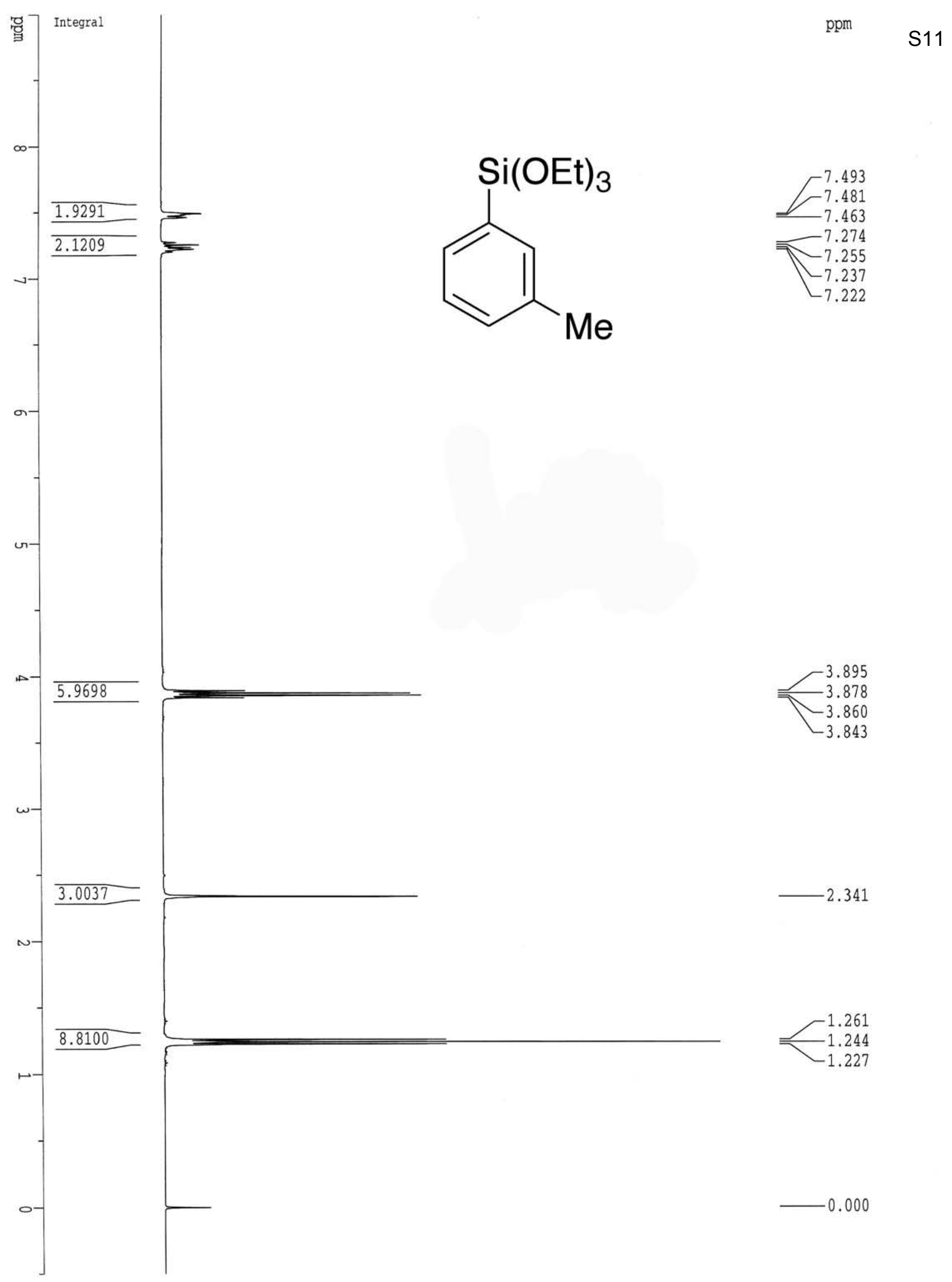

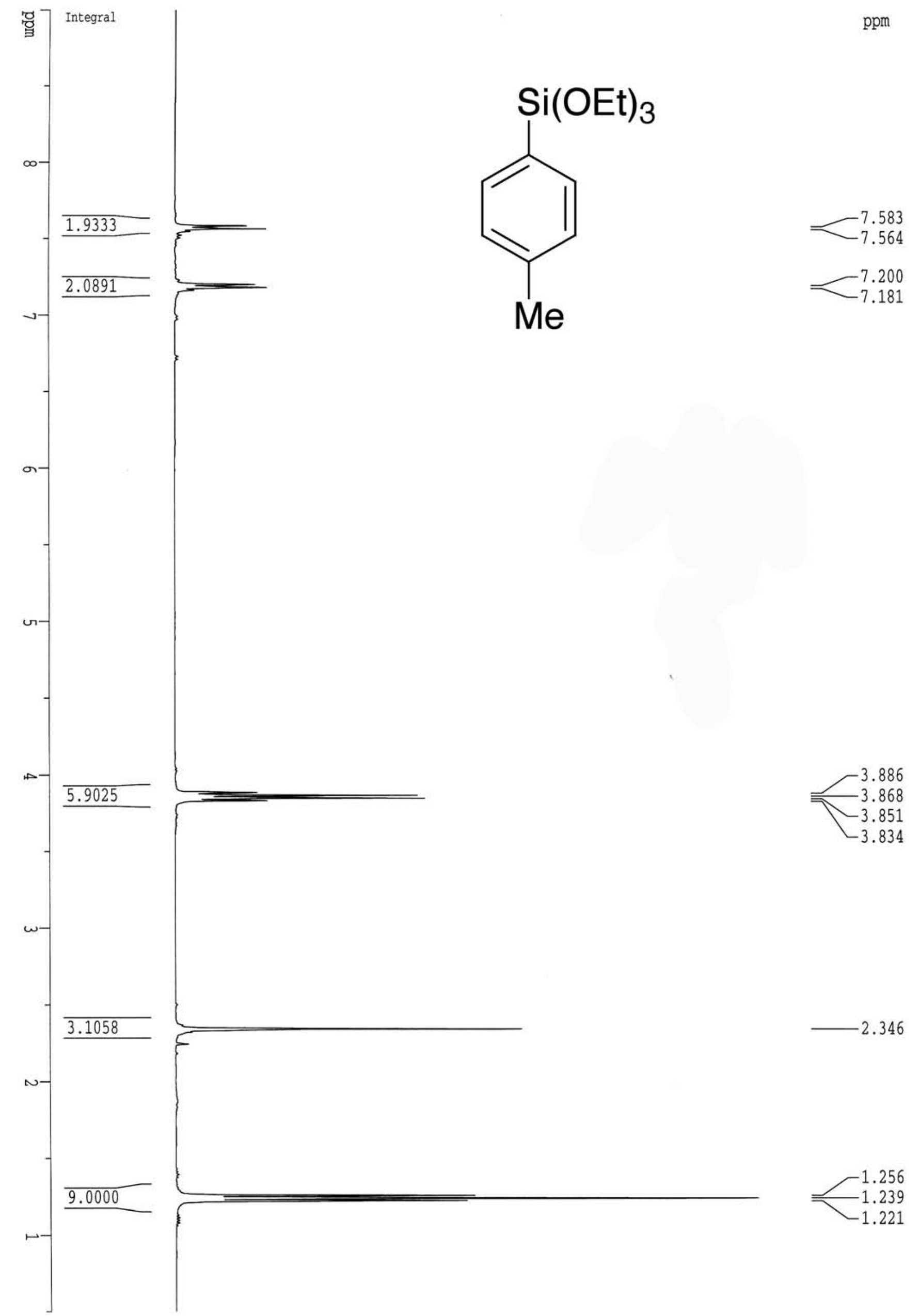


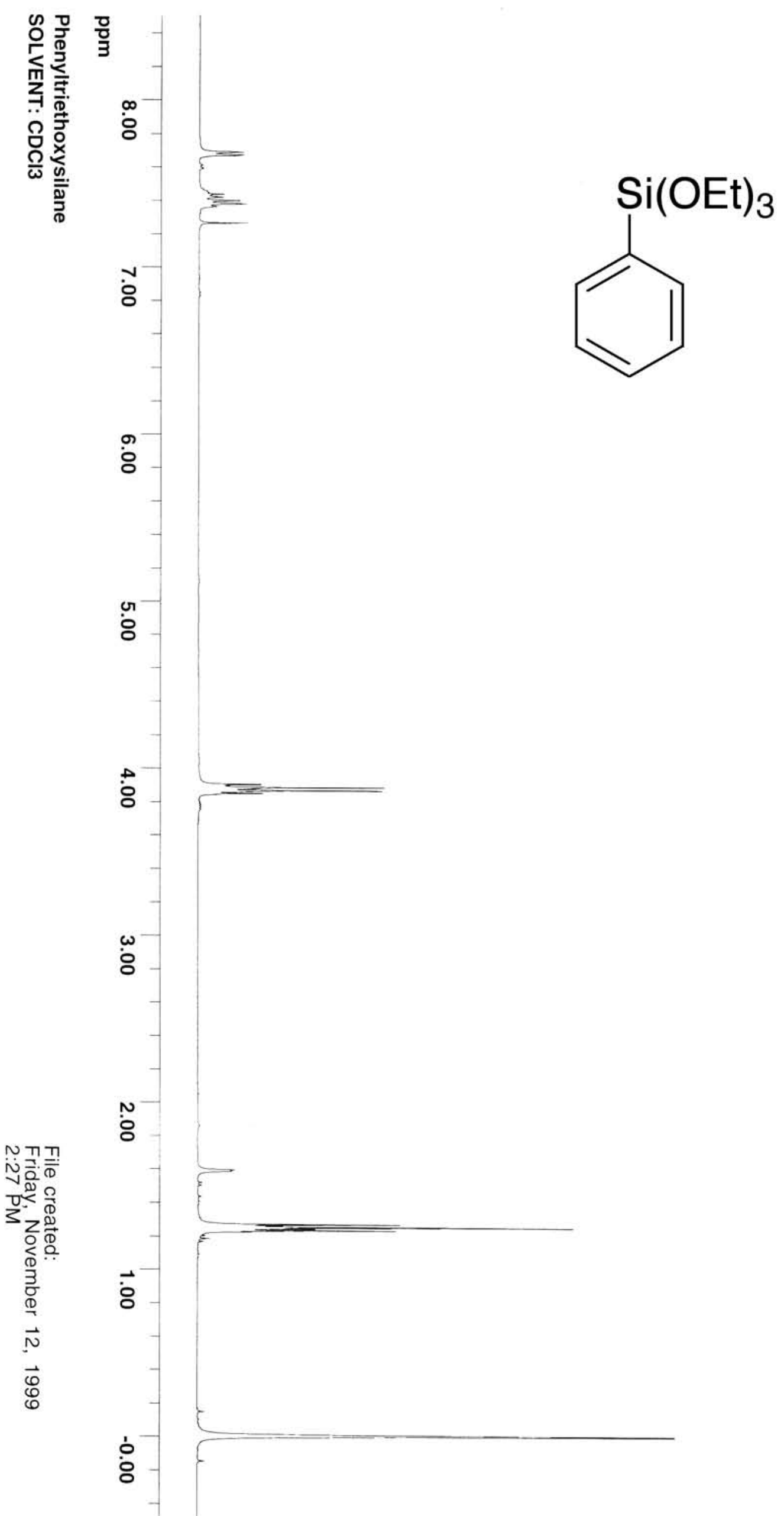




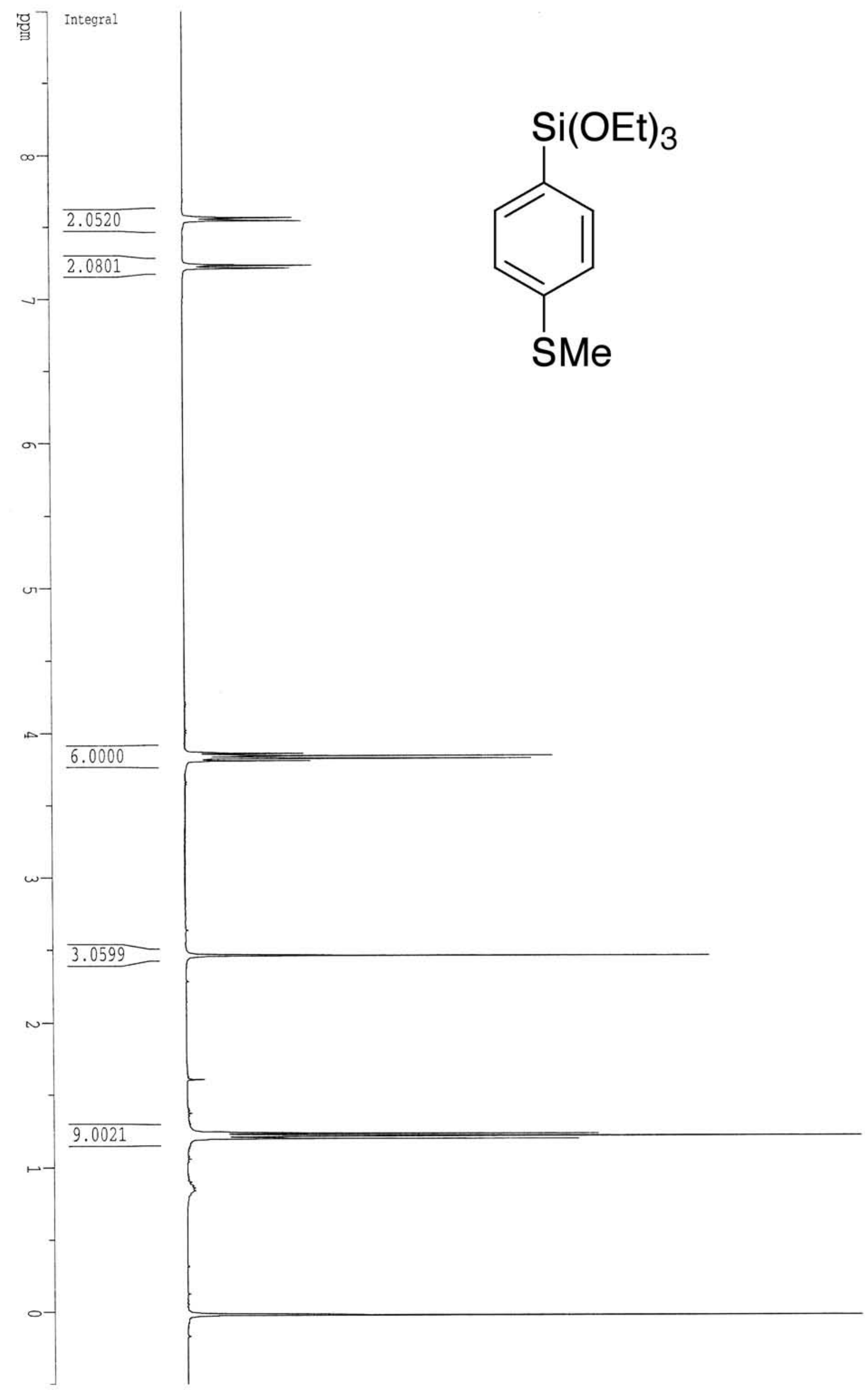




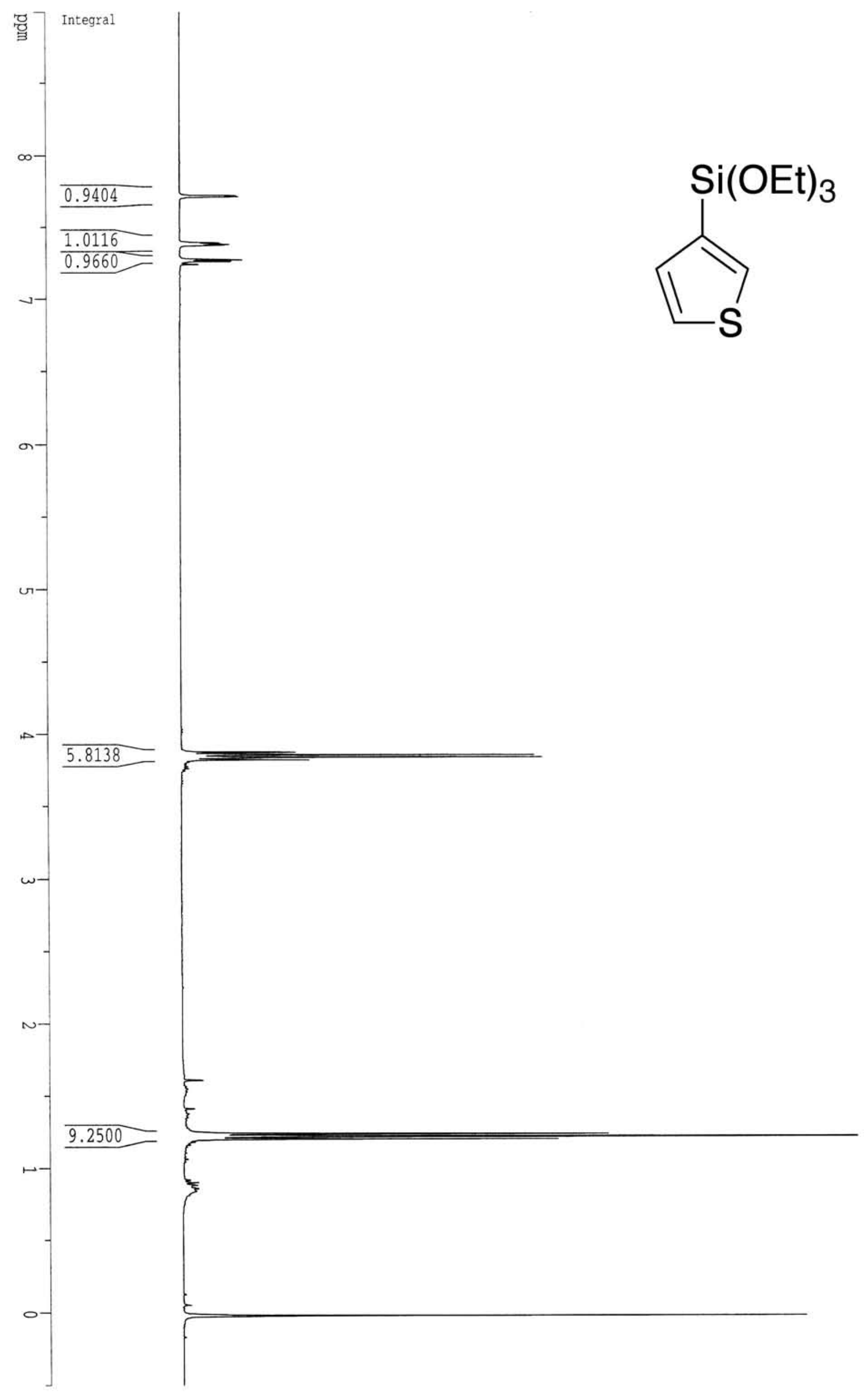




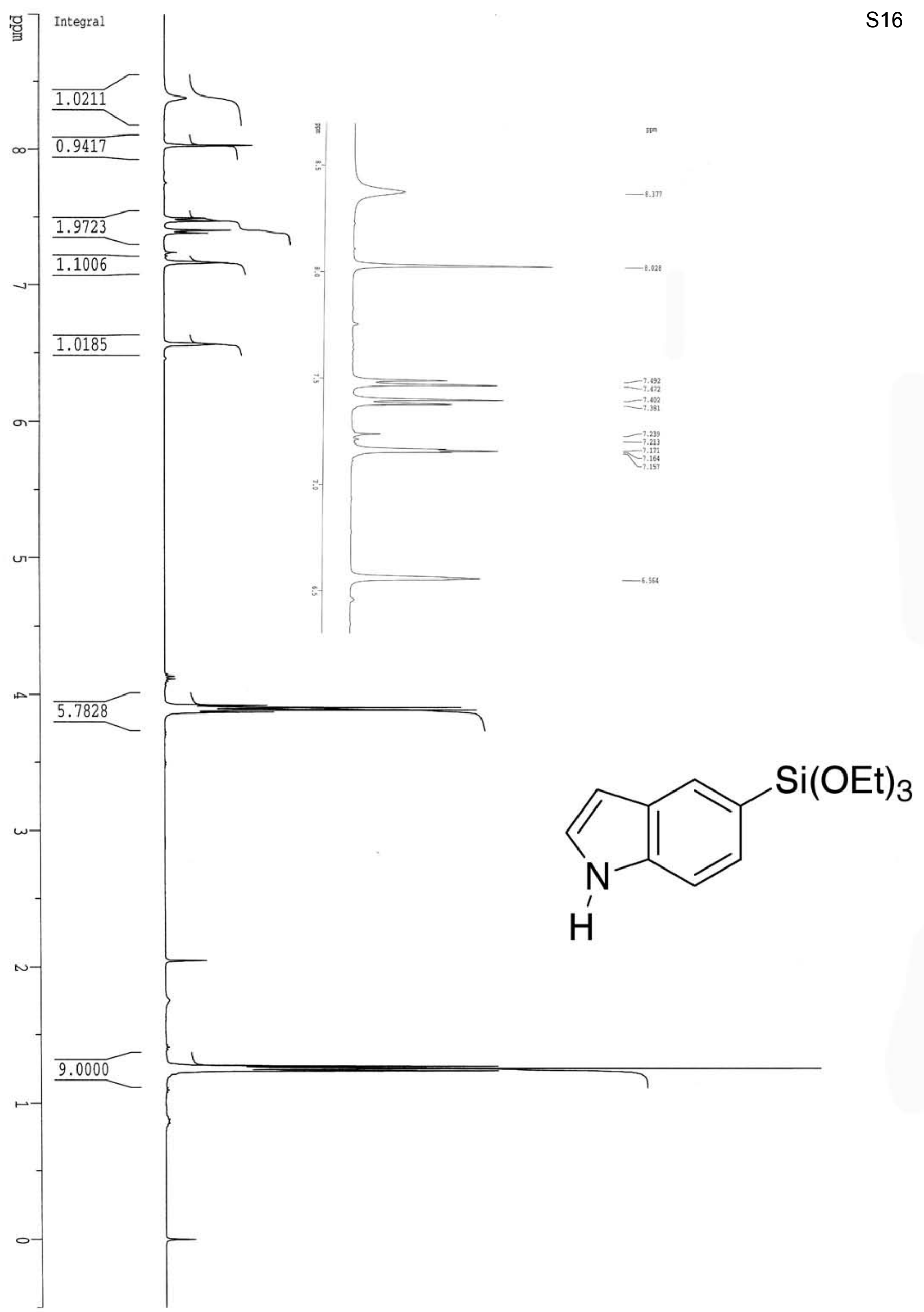




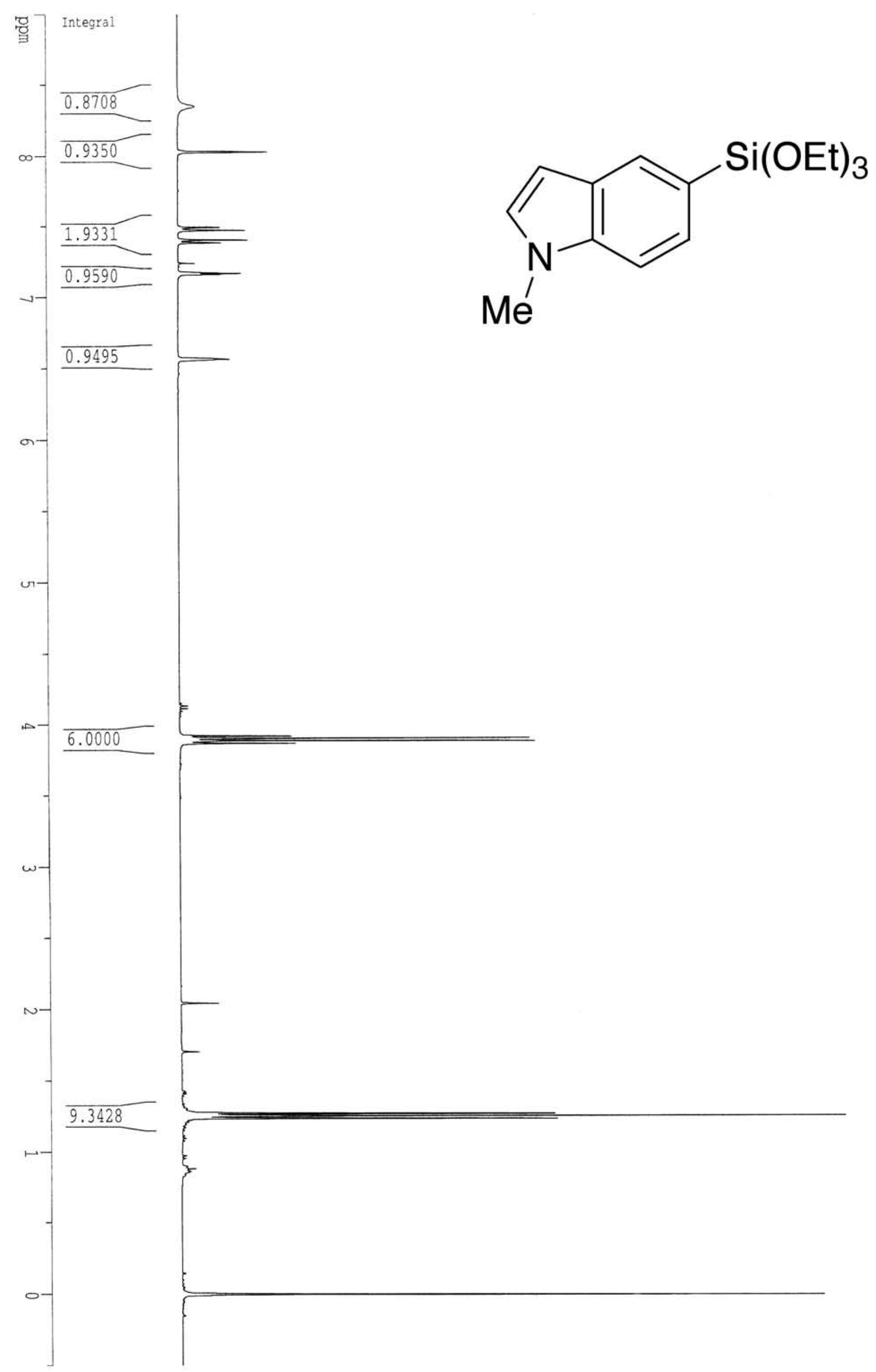


㽜

Integra

T.663

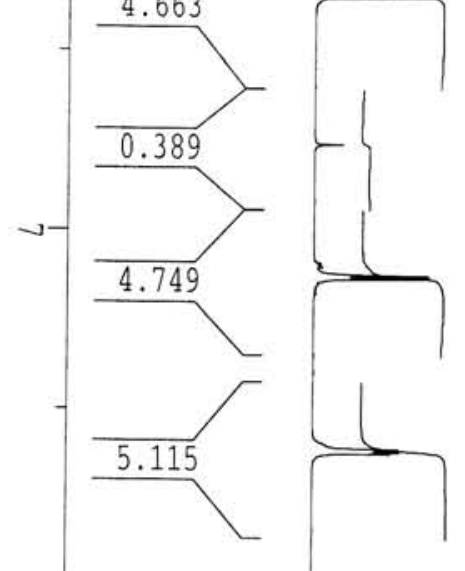

$a-$$$
\text { 更 }
$$
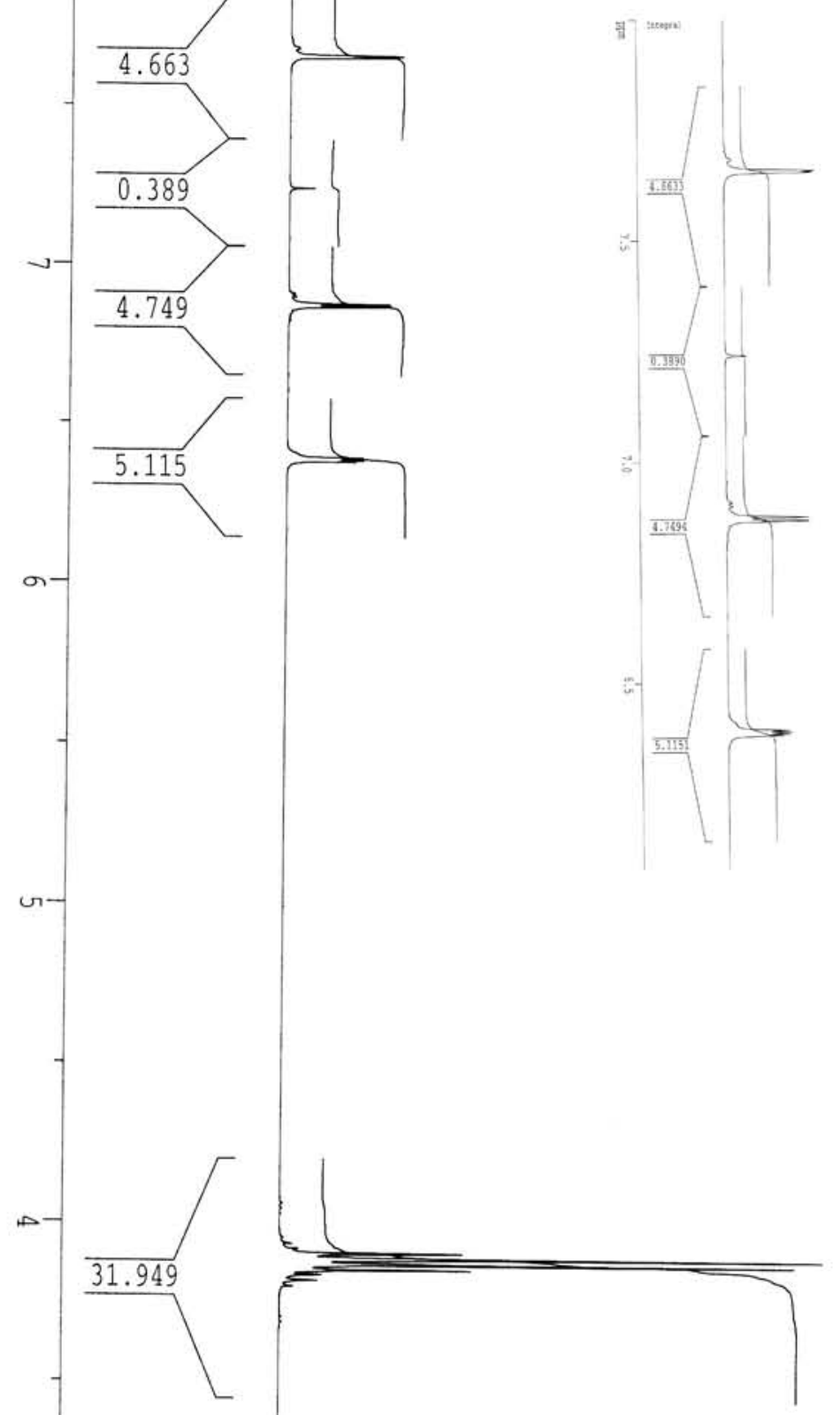


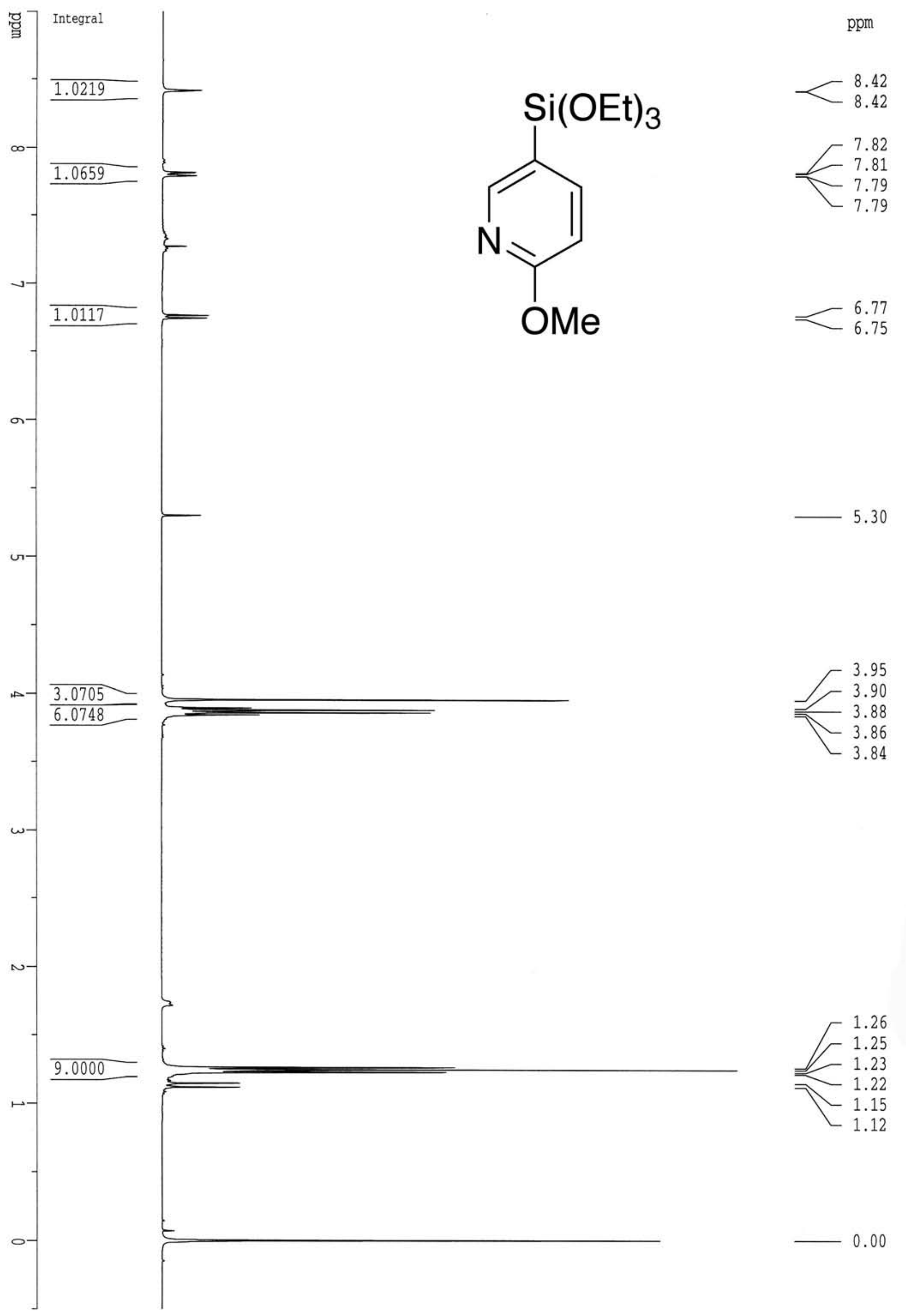

